\title{
Climate Change and Florida: Frequently Asked Questions ${ }^{1}$
}

\author{
Joshua Papacek, Ashley Smyth, Holly Abeels, and Alicia Betancourt ${ }^{2}$
}

\section{Introduction}

Climate change is considered one of the biggest challenges facing society. As global temperatures continue to rise, we are threatened by melting ice sheets, rising sea levels, and extreme weather events. Climate change is also something that people in south Florida live with daily. Still, the science of climate change is complicated, leaving many in the region looking for trusted information about why climate should matter to them. The purpose of this FAQ document is to provide answers to commonly asked questions regarding climate change. The questions come from south Florida residents and municipal workers concerned with the climate outcomes to their region. The FAQ addresses several areas of concerns, including the basic science behind climate change, the projected impacts to residents of south Florida, and actions that individuals can take to reduce their carbon footprints.

\section{Climate Science Basics}

\section{What is the difference between weather and climate?}

Weather is the day-to-day conditions in temperature, precipitation, humidity, and other conditions that we experience in a particular geographic area. Climate, on the other hand, is a long-term average of these conditions. Climate can be measured on different scales from seasonal to annual (or longer) in length and from regional to global in size. Although climate is complex, we can use past observations to make future predictions. For example, much of Florida experiences a "wet" season and a "dry" season. While we would expect that more rain will fall during the months of the wet season, within the season there is significant variability in daily rainfall amounts.

\section{What is the right name for this phenomenon, climate change or global warming?}

Although both terms are sometimes used interchangeably in daily conversation, scientists use them to refer to specific observations. Global warming is a narrower term that refers to the long-term trend of rising global temperatures. Although average global temperatures are increasing, not all areas of the planet are warming at the same rate. For example, the arctic (i.e., higher-latitude) regions show the greatest deviations in average temperatures and appear to be more sensitive to warming compared to lower latitudes. Because warmer temperatures from global warming can cause a multitude of extreme events and changing conditions across the globe, climate scientists typically refer to these collective changes over time as "climate change."

1. This document is SL469, one of a series of the Department of Soil and Water Sciences, UF/IFAS Extension. Original publication date August 2020. Visit the EDIS website at https://edis.ifas.ufl.edu for the currently supported version of this publication.

2. Joshua Papacek, graduate student; Ashley Smyth, assistant professor, Department of Soil and Water Sciences, UF/IFAS Tropical Research and Education Center; Holly Abeels, UF/IFAS Florida Sea Grant agent, UF/IFAS Extension Brevard County; and Alicia Betancourt, County Extension director, UF/IFAS Extension Monroe County; UF/IFAS Extension, Gainesville, FL 32611.

The Institute of Food and Agricultural Sciences (IFAS) is an Equal Opportunity Institution authorized to provide research, educational information and other services

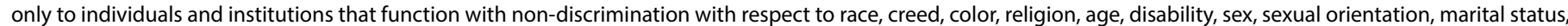

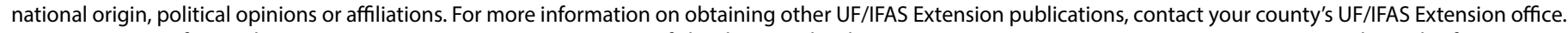
U.S. Department of Agriculture, UF/IFAS Extension Service, University of Florida, IFAS, Florida A \& M University Cooperative Extension Program, and Boards of County Commissioners Cooperating. Nick T. Place, dean for UF/IFAS Extension. 


\section{How do we know the climate is changing?}

Several lines of evidence strongly suggest the modern climate is changing. The most direct impact of climate change is through global warming; average global surface temperatures have risen approximately $0.8^{\circ} \mathrm{C}$ over the last century (Figure 1). Other indicators of climate change are shrinking ice sheets, sea-level rise, ocean acidification, and as mentioned above, increasing extreme-weather events (NASA). Some of these impacts are discussed in more detail below.

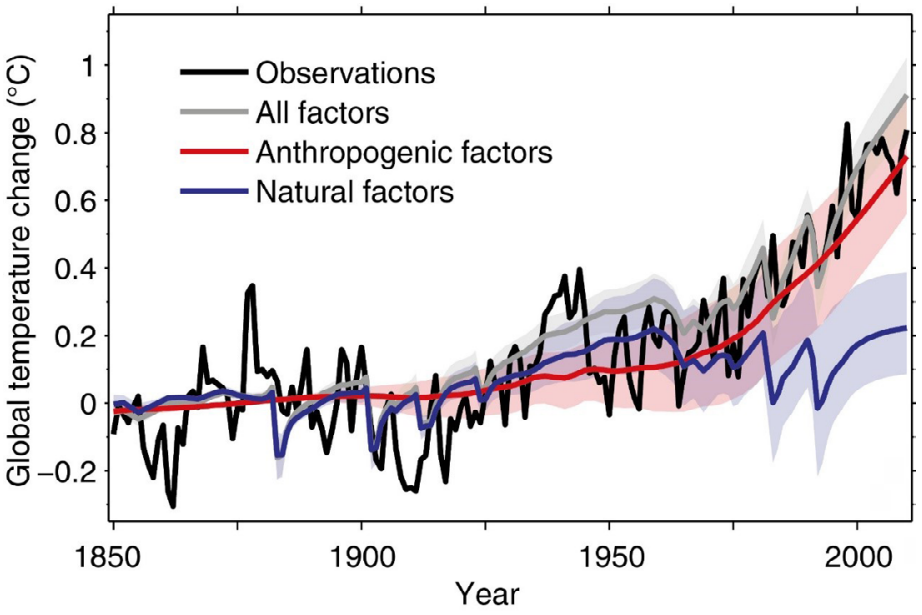

Figure 1. Temperature change simulations from anthropogenic (or human-caused) factors (red line), natural factors (blue line), and a combination of factors (gray line) compared to the observed temperature change globally (black line).

Credits: Huber and Knutti 2011

\section{Hasn't the planet's climate changed in the past? How do we know that climate change is caused by humans this time?}

Yes, Earth's climate has changed significantly in the past. Scientists have recorded these past changes and attributed them to several factors, including changes in solar activity, atmospheric conditions, and major geologic events, such as volcanic eruptions. However, current trends show a more rapid increase in global temperatures and $\mathrm{CO}_{2}$ concentrations relative to any other time in human history. For example, ice core records of $\mathrm{CO}_{2}$, a greenhouse gas, show that current concentrations (reaching $>415 \mathrm{ppm}$ in 2019) are higher than at any time in the last 800,000 years (Luthi et al. 2008). Additionally, the combined effects of other major drivers of climate change do not accurately explain the modern records of warming and, in some cases, are going in the opposite direction of this warming trend. Only when scientists include anthropogenic (i.e., human) sources is the warming trend explained. These human contributions, primarily through greenhouse gas (GHG) emissions, are by far the largest climate "fingerprint" contributing to global warming and climate change (Figure 1).

\section{What are greenhouse gasses and where do they come from?}

A greenhouse gas (GHG) is any gas that contributes to the "greenhouse effect." Various gasses, such as carbon dioxide $\left(\mathrm{CO}_{2}\right)$, methane $\left(\mathrm{CH}_{4}\right)$, and nitrous oxide $\left(\mathrm{N}_{2} \mathrm{O}\right)$, trap heat from solar energy in the earth's atmosphere. Thus, like a greenhouse, GHGs warm the earth and keep it habitable by not allowing all the heat to escape the atmosphere. As concentrations of GHGs have significantly increased, the amount of heat trapped on earth has significantly increased (Figure 2). GHGs also vary in their ability to trap heat. In fact, $\mathrm{N}_{2} \mathrm{O}$ traps more heat than $\mathrm{CO}_{2}$ and $\mathrm{CH}_{4} \cdot \mathrm{N}_{2} \mathrm{O}, \mathrm{CH}_{4}$, and $\mathrm{CO}_{2}$ are emitted through fossil fuel production and burning, while agriculture and waste treatment also emit $\mathrm{N}_{2} \mathrm{O}$ and $\mathrm{CH}_{4}$. It is common to talk about GHGs in terms of $\mathrm{CO}_{2}$ equivalent, which is the amount of warming a gas may cause, using $\mathrm{CO}_{2}$ as reference.

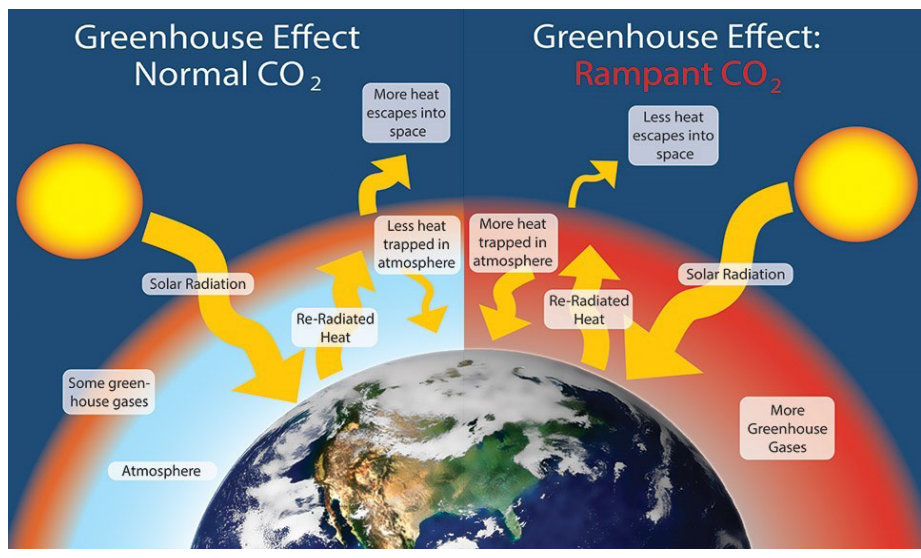

Figure 2. Left: the natural effect of GHG is to trap heat from solar radiation and warm the planet. Right: increased GHG emissions, including $\mathrm{CO}_{2}$, from human activity increase the amount of heat trapped in the Earth's atmosphere.

Credits: Will Elder, National Park Service

Many processes can be a source of GHGs, by adding them to the atmosphere, or a sink, by removing them. For GHGs such as $\mathrm{CO}_{2}$ and $\mathrm{CH}_{4}$, this movement of carbon is collectively known as the carbon cycle (Fig. 3). The burning of fossil fuels for electricity, transportation, building, and industrial uses contributes most significantly to anthropogenic $\mathrm{CO}_{2}$ emissions (EPA). Another major source of GHGs is changing land use (Figure 3). Forests, grasslands, and wetlands-both inland and coastal-act as important "sinks" of $\mathrm{CO}_{2}$ by storing carbon in their vegetation and soils. In fact, estimates suggest coastal wetlands (i.e., seagrass, mangroves, and salt marshes) in the United States alone sequester 8.1 million metric tons of $\mathrm{CO}_{2}$ every year (EPA report 2019). But increasing pressure from agricultural and urban needs has altered, removed, or degraded these ecosystems so they can no longer sequester $\mathrm{CO}_{2}$ from the atmosphere as efficiently. Ultimately, the combined 
effects of human activity are increasing GHG concentrations, reducing the ability for the earth to sequester GHGs, and warming the planet through the greenhouse effect.

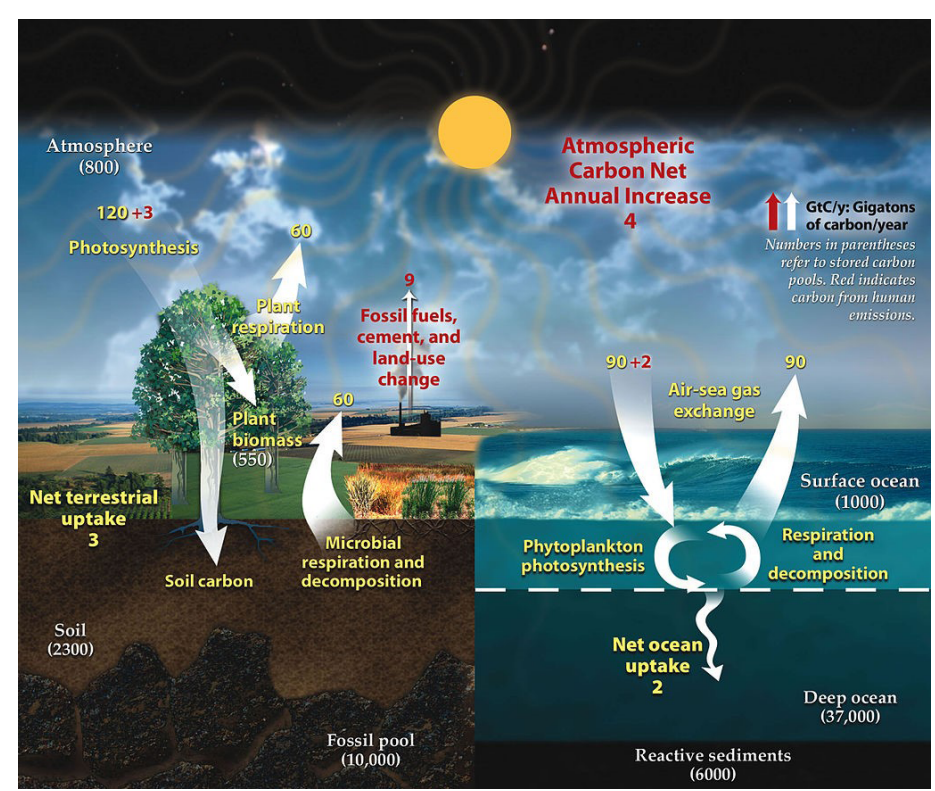

Figure 3. The carbon cycle is the movement of carbon from different compartments on land (left), in the ocean (right), and in the atmosphere. Yellow numbers are from natural sources of carbon emissions while red numbers are from human, or anthropogenic, sources. White numbers in parentheses are from sinks or pools where carbon is stored.

Credits: US D.O.E. 2008

\section{Which is worse: methane or carbon dioxide?}

There are chemical differences between methane, $\mathrm{CO}_{2}$, and other GHGs that control how much heat they trap and how long they remain in the atmosphere once emitted. Because $\mathrm{CO}_{2}$ is still the largest individual contributor to overall GHG emissions, scientists use it as the baseline for calculating global warming potential (GWP). For example, despite its relatively short lifetime in the atmosphere, methane is so efficient at trapping heat that it has a GWP 30 times greater than $\mathrm{CO}_{2}$. Nitrous oxide $\left(\mathrm{N}_{2} \mathrm{O}\right)$ is even more potent with a GWP 265-298 times greater than $\mathrm{CO}_{2}$ (EPA). Although both gasses are naturally found in smaller concentrations than $\mathrm{CO}_{2}$, their larger GWPs mean rising emissions of these gasses from human activity are a growing concern.

\section{How are scientists sure about warming when the climate computer models are uncertain? Is there actually scientific consensus on climate change?}

Climate models are mathematical representations of the many moving parts that interact with Earth's climate. Climate scientists use climate models based on past climate conditions to make predictions about the future. While there is uncertainty in these predictions, several previous predictions about the modern climate are now confirmed by observations. Uncertainties tend to be larger the further in the future we try to predict, but they still give us an accurate overall trend and the major effects we can expect. Based on these confirmations, more than $90 \%$ of scientists who study the climate agree that humans are the main cause of climate change (Cook et al. 2016).

\section{Climate Change Impacts Is climate changing in Florida, and what are the long-term projections?}

Scientists can use long-term trends in temperature and rainfall to determine how climate is changing and may continue to change in Florida's future. Importantly, while global temperatures have accelerated with rising GHG emissions, local temperatures may fluctuate due to several factors, such as land use. For example, urban areas tend to be warmer than rural areas due to the urban "heat island" effect.

Throughout the southeastern United States, many cities are experiencing hotter days, warmer nights, or a combination of these as the global climate warms (Figure 4A-B). However, the degree of warming across this part of the country is less noticeable over the last 100 years than in other regions of the United States. Scientists have attributed the relative warming deficit to natural and anthropogenic causes, but importantly, they project that warming will still continue (Meehl 2012; NCA 2018). This prediction is based on the significant warming trend in the last decade, with four of Florida's hottest years on record occurring since 2015. Summer temperatures in Florida have increased by roughly $1^{\circ} \mathrm{F}$ since 1950 , and in the next 20 years, average summer temperatures are projected to rise above $83^{\circ} \mathrm{F}$ under both moderate and high emissions scenarios. From 1981 to 2010, Floridians experienced, on average, high temperatures exceeding $95^{\circ} \mathrm{F}$ roughly 7 days per year. Under moderate and high emissions scenarios, this number is projected to rise to 22 and 26 days per year, respectively (Hsiang et al. 2017; see Climate Impact Lab data visualization tool).

As mentioned, climate predictions are based on a range of plausible climate scenarios. Part of these scenarios are based on predictions of future human decisions, such as our reliance on fossil fuels and our GHG emissions (Kayhoe et al. 2017). When discussing climate projections, it is also important to note there are technical difficulties in downsizing the large-scale global models to smaller, 
regional predictions. For a state like Florida, climate projections are complicated by its narrowness and the importance of the ocean to our climate patterns (Kirtman et al. 2017). Rainfall patterns in Florida are expected to be impacted by climate change as well. While there is no clear regional trend in average precipitation, there is an increase in days with extreme precipitation events (Figure 4C), and this trend is predicted to continue in the future. As summer temperatures rise, droughts will also likely be more intense in Florida. Scientists, local governments, and natural resource managers can also use scenario-based approaches (e.g., $\pm 10 \%$ rainfall) to account for the uncertainty in regional climate models when making predictions about local impacts.

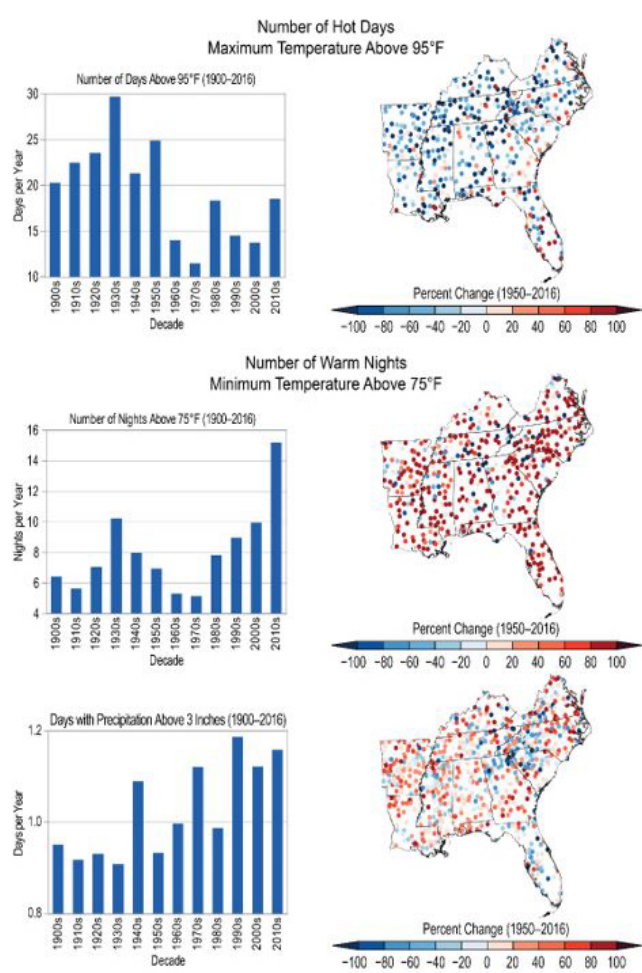

Figure 4. Decadal trends in the number of hot days (A), warm nights (B), and extreme rainfall events (C) in cities across the southeastern United States from 1900-present.

Credits: edited from NCA 2018, original figures 19.1 and 19.3

\section{Why are the sea levels rising?}

Sea-level rise (SLR) is one major effect of rising temperatures. As water gets warmer, it physically expands to a greater volume. Another major contributor is the melting of land-based ice that is otherwise frozen in ice sheets.

These effects have combined to increase the total volume of water in the global oceans, otherwise known as "eustatic sea level." However, local sea-level rise can be smaller or larger than global trends due to the geology or human impacts to the topography of an area and changes in ocean circulation patterns. Florida's long coastline and low-lying land make it particularly vulnerable to the damaging impacts of sea-level rise. In south Florida, SLR projections expect increases of between $6-10$ inches by 2030 and 14-26 inches by 2060 (Fig. 5; SE FL Climate Compact). Projections have also been made in other regions of the state, including Tampa Bay (Tampa Bay Climate Science Advisory Panel). Using common SLR projections throughout a region allows for improved planning and coordination among local governments.

The range of SLR estimates is another important example of model uncertainty. Estimates based on data from the International Panel on Climate Change (IPCC), the US Army Core of Engineers (USACE), and the National Oceanic and Atmospheric Administration (NOAA) show different trajectories for south Florida (Figure 5). One major reason these numbers differ is because of uncertainty about how much the accelerated melting of land-based ice will contribute to SLR (SE FL Climate Compact). Despite these uncertainties, it is important for local governments to have these projections available to assess how vulnerable their cities are to SLR. Every additional inch of sea-level rise will increase the economic risks Florida faces from flooding, which will threaten more property and infrastructure. Decision-makers will need to consider a variety of factors when planning to balance the costs of adapting to higher projections versus these potential risks.

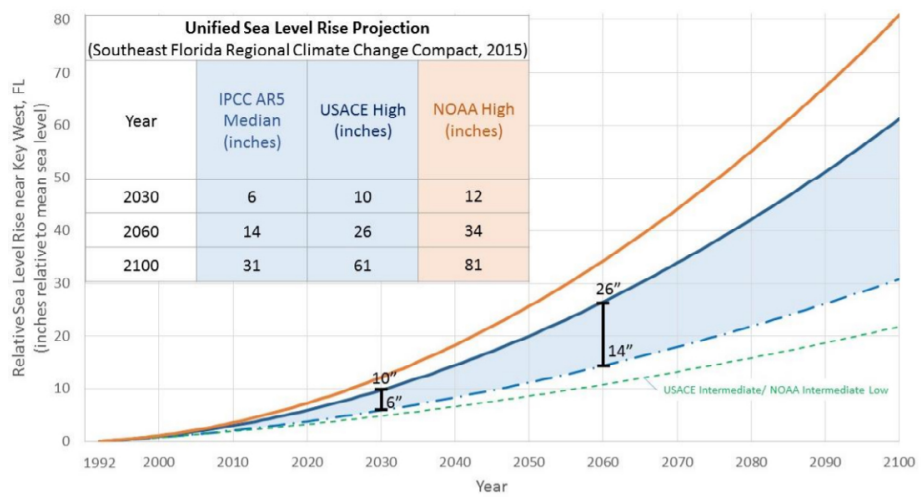

Figure 5. Unified SLR projections for south Florida in reference to mean sea level at the Key West tide gauge. The range of blue lines is used for regional planning purposes. Credits: SE FL Climate Compact (2015)

\section{Will climate change cause more extreme events? What about hurricanes in Florida?}

Connecting climate change to a single weather event is difficult, but recent studies have shown that collectively, extreme-weather events are linked to climate change. For example, stronger storm events and increased precipitation are projected in some areas because warmer air can hold more moisture. In others, drought may be more pronounced as extreme heat days become more common and 
water evaporates more quickly (Mueller and Seneviratne 2012). Some changes to weather may seem paradoxical. As the arctic is warming at much quicker rates than the rest of the planet, this disturbance is pushing colder winters and extreme winter-storm events into the northern United States (Cohen et al. 2018). These dramatic shifts between hot and cold, flooding and drought, are sometimes termed "weather whiplash."

Here in Florida, the low topography makes us particularly vulnerable to increasing sea levels combined with storm surge from tropical storms and hurricanes. While there is less evidence that hurricane frequency alone is increasing due to warmer temperatures, studies show that individual hurricanes can intensify rapidly but also move more slowly when they form over warmer ocean waters and in air holding more moisture. These hurricane events have strong winds and lots of rain. Recent storms to hit the southeastern United States-Hurricanes Harvey, Irma, and Maria in 2017 and Hurricanes Florence and Michael in 2018-were all examples of hurricanes with greater wind speeds or rainfall totals because of climate change (NCA 2018).

\section{Will climate change affect my home's value?}

Many factors can affect real estate value, and climate change is likely to become an increasing factor in determining a home's value. Climate change could impact your home's value in several ways, including:

- Physical risk from increasing catastrophic events

- Less demand for waterfront homes

- Higher insurance premiums

- Higher property taxes

- Increased property values for some homeowners

Physical risks are those caused directly by specific catastrophic events-hurricanes, sea-level rise, drought, wildfires. These events could increase the costs of maintaining, repairing, and reconstructing structures, the costs of property insurance, and postevent business and economic productivity losses.

Other climate impacts to homeowners will be transition risks, such as the depression of real estate market growth as well as property values. Communities who see recurrent impacts may have increased investment and ownership expenses through property taxes and insurance premiums (Urban Land Institute 2019). Areas that are more resilient to climate-change impacts will likely see a benefit in increased property values over time. Communities that plan and adapt to climate change will lessen some of the effects on value and insurance.

\section{How will climate change impact water quality and aquatic resources in Florida?}

In addition to flooding, sea-level rise is a significant risk to potable freshwater supply due to the low elevation and underlying geology of our state. For example, Broward and Miami-Dade Counties have already lost freshwater drinking wells near the coast due to saltwater intrusion. Climate change is also expected to impact water quality by increasing the severity of toxic algae in our waterways; toxic algae are more likely to bloom during periods of warmer temperatures and increased nutrient runoff from stronger storms (Havens 2018). Additionally, climate change is already impacting Florida's coastal ecosystems. Elevated ocean temperatures can trigger coral bleaching, a physiological response by corals to stress that causes them to turn white. The low-lying Everglades are particularly susceptible to SLR, and previously freshwater wetlands can physically collapse due to saltwater intrusion. In turn, the services these coastal and wetlands resources provide southeastern Floridians are expected to be impacted with climate change (Florida Climate Institute).

\section{How else is climate change already affecting my life or the lives of others? How will future climate change affect my everyday life?}

Climate events are already impacting the daily lives of Floridians, both in urban and rural environments. Stronger storms will negatively impact travel conditions, and in coastal Florida, "sunny day" flooding has already been a noticeable issue for many residents (Figure 6). The increased flooding risks from SLR and storms is also reducing access to affordable housing on higher ground (see: climate gentrification). Multiple stressors from climate change are also expected to cause harm to communities reliant on agriculture, aquaculture, and tourism (NCA 2018).

Furthermore, "extreme-heat days" (i.e., days above $90^{\circ} \mathrm{F}$ ) have already been increasing in the southeastern United States, and more extreme heat waves are expected to continue in many Florida cities (NCA 2018). Extreme heat can have severe consequences for human health by increasing cases of heat exhaustion for outdoor workers, older residents, and those without shelter or air conditioning. Warmer temperatures overall will also exacerbate asthma, allergy symptoms, and other medical conditions. 


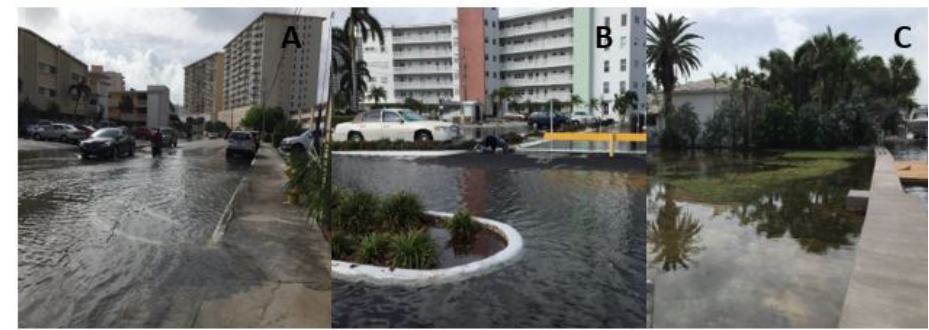

Figure 6. The 2017 King Tides bubbled up into parking lots (A-B) and overtopped seawalls (C) in Hallandale Beach (Broward County, FL). Since then, some adaptation measures have been taken to reduce the impacts of tidal flooding, which are expected to increase with SLR. Credits: City of Hallandale Beach

\section{What is the ozone layer's role in climate change?}

Ozone $\left(\mathrm{O}_{3}\right)$ usually forms very high in the atmosphere, where it can absorb some sunlight in the form of UV light and protect us from this damaging radiation. The current hole in the ozone layer is probably too small to be contributing significantly to the increased temperatures globally. However, ozone also forms near us at the Earth's surface from sunlight and chemical reactions, and its chance of forming increases during hot, sunny days. When it collects in high concentrations, ozone becomes a significant pollutant, can act like a GHG by trapping heat, and can make it harder to breathe.

The impact of ground-level ozone is amplified in urban areas due to additional sources of air pollution and the urban heat-island effect. The state of Florida, in cooperation with several localities, monitors ozone and other air pollutants in major Florida cities (Florida DEP). While air quality has been improving across Florida, continued progress will be more difficult as the climate changes.

\section{Are there benefits to a warming climate?}

There is evidence that increasing temperatures and $\mathrm{CO}_{2}$ may increase plant productivity and growth in temperate climates, but climate change is expected to significantly impact agriculture and Florida's economy. For example, some crops may become more viable under warmer temperatures, but many crops and livestock important to Florida's economy will respond negatively to hotter growing seasons, water stress, and new diseases and pests (Her et al. 2017). Additionally, crops grown under high- $\mathrm{CO}_{2}$ conditions may actually become less nutritious over time (Myers et al. 2014).

As mentioned, some climate models predict more intense rainfall events in Florida. Under these conditions, soils cannot hold on to all of the extra water, which will instead run off from fields. Similarly, under increased drought conditions, the need for irrigation further strains our water resources. Ultimately, the costs of rising temperatures and changing rain patterns to plants means that any benefits may be localized and short-lived.

\section{Taking Action}

\section{Can we reverse global warming?}

There are several proposed technologies, often dubbed "geoengineering," which propose to capture and sequester atmospheric $\mathrm{CO}_{2}$ to reduce concentrations to preindustrial levels. These technologies are not currently feasible on the scale needed to completely reverse current warming, and there is no scientific consensus on the safety of these techniques. However, there are other actions we can take to both mitigate the severity of climate change and adapt to future impacts.

\section{What is the difference between mitigation and adaptation?}

We can classify response to climate change as either mitigation or adaptation. Climate mitigation is any effort to reduce or stabilize the current trajectory of carbon emissions and warming. For example, reducing your "carbon footprint" by using less fossil fuel is one way to mitigate climate change. Some examples of ways to reduce your carbon footprint are discussed below. Climate adaptation includes any actions that try to reduce the impacts of current or projected changes. Some examples of climate adaptation are also discussed below.

\section{What is a carbon footprint and how can I reduce mine?}

Your carbon footprint is how much carbon emissions you contribute over a certain timeframe. It is typically calculated based on the transportation you use, your diet, how energy efficient your home is, and other aspects of your day-to-day life. Some common ways to reduce carbon footprint and conserve resources in general are:

- Cut fossil fuel use by travelling less and increasing use of bikes, carpools, or public transit to travel.

- Reduce overall waste before reusing or recycling.

- Avoid single-use plastic consumption.

- Reduce food waste by cooking more efficiently and composting organic waste.

- Eat a more plant-rich diet, and eat more locally and in-season. See https://drawdown.org/solutions/plantrich-diets for details. 
- Save water indoors by installing low-flow faucets, shower heads, and toilets.

- Be aware of weather conditions before watering outdoor plants.

- Design landscaping with native plants to meet your local climate and water needs. See the Florida-Friendly Landscaping ${ }^{\mathrm{TM}}$ website for ideas.

- Use less electricity by switching to energy-efficient appliances, electronics, and lightbulbs.

- Invest in insulation and weatherization products to reduce heating/cooling needs.

- Promote and protect natural and artificial "green" spaces that sequester GHGs.

\section{What is the government's role in addressing climate change?}

Federal, state, and local governments have a role in the effort to address climate change impacts through mitigation and adaptation. The government can mitigate, or reduce, GHG emission through adoption of policies that increase fuel- and energy-efficiency standards and increase cleanenergy production, such as wind or solar. Many cities in Florida have taken the lead on reducing their own carbon footprints. In 2016, St. Petersburg became the first in the state to commit to $100 \%$ renewable energy (by 2035), and several cities have followed with similar commitments. Like an individual carbon footprint, an important first step to reducing a city's carbon footprint is conducting a GHG inventory and targeting specific activities to reduce emissions. In southeast Florida, most emissions come from transportation, followed by residential and commercial energy (SE Florida Climate Compact).

Governments also protect people and investments through adaptation to reduce the predicted impacts of climate change. Florida governments have many tools to address climate change, including a state statute to allow local governments to include "Adaptation Action Areas" in their comprehensive plans. These are areas that are vulnerable to the related impacts of rising sea levels for prioritizing funding for infrastructure needs and adaptation planning (\$163.3164(1), F.S. 2011). Cities can build seawalls, pumps, or raise roads to reduce the effects of flooding from SLR. Building codes and zoning laws make homes and structures more resilient to impacts such as flooding and fires. Many governments conduct vulnerability studies to determine the risk of climate impacts to critical infrastructure and vulnerable populations. Hallandale Beach has installed TideFlex Check Valves to reduce high-tide flooding and the impacts of sea-level rise in low-lying parts of the city. Cities are also finding ways to adapt to extreme heat. For example, in 2018, the City of West Palm Beach passed an ordinance increasing the required amount of shade designed into new construction, emphasizing that at least $75 \%$ of trees planted in new parking lots must be shade-providing trees.

Lastly, local governments help communities address climate change through raising awareness of climate change impacts and engaging experts in locally relevant solutions.

\section{Talking about Climate Change Do you have any quick tips for communicating about climate change?}

Engaging in meaningful conversations about climate change is important-most people do not talk about climate change on a daily basis. These conversations are the easiest way to share your knowledge and help others have a better understanding of the issue. The first consideration is to understand who you are talking to. Research has shown that most Americans believe that climate change is a threat (and that percentage is growing), but you can still connect over shared values with those who are disengaged with the issue (Yale Climate Communications). Lastly, it is advised to steer away from "doom and gloom" when talking with people who are already aware. Instead, focus on telling people what they can do to help and motivate them to take action.

\section{What are reputable sources about climate change that are available to the public?}

Although much of the current climate science is published in scientific journals, some of this research is not publicly accessible. Fortunately, several US government agencies are tasked through a Congressional mandate to release a report summarizing the most up-to-date climate science, including new warming and SLR projections, impacts to humans, and current adaptation and mitigation progress. In 2018, the fourth National Climate Assessment (NCA) was released, and importantly, the NCA includes summary reports for geographic regions (e.g., the southeastern United States), which is more helpful when discussing local impacts. Additionally, many of the individual federal agencies have separate websites with climate data and FAQs available:

- NASA Climate FAQ

- NOAA/climate.gov Global Warming FAQ

- EPA Climate Indicators FAQ

- CDC Climate Effects on Health and Fact Sheets 


\section{Acknowledgements}

The authors wish to thank Alyssa Jones-Wood (City of Hallandale Beach), Dr. Colin Polsky (Florida Atlantic

University) and Dr. Willm Martens-Habbena for assistance with a panel discussion with staff from the City of Hal-

landale Beach, where many of the questions originated. 